\title{
PERANAN PENDIRIAN BADAN USAHA MILIK NAGARI BERDASARKAN UNDANG-UNDANG NOMOR 6 TAHUN 2014 TENTANG DESA DALAM UPAYA PENINGKATAN EKONOMI MASYARAKAT DI NAGARI CUPAK KECAMATAN GUNUNG TALANG KABUPATEN SOLOK.
}

\author{
Yulia Risa \\ Fakultas Hukum, Universitas Dharma Andalas \\ E-mail : yuliarisa24@gmail.com \\ Engrina Fauzi \\ Fakultas Hukum, Universitas Dharma Andalas \\ Jelisye Putri Cenery \\ Fakultas Hukum, Universitas Dharma Andalas
}

\begin{abstract}
Abstrak
Penelitian ini bertujuan untuk menggambarkan dan memahami pertama, bagaimana mekanisme pendirian Badan Usaha Milik Nagari (BUMNag) di Nagari Cupak, kecamatan Gunung Talang Kabupaten Solok kedua, bagaimakah peranan Badan Usaha Milik Nagari (BUMNag) dalam peningkatan kesejahteran masyarakat Nagari Cupak Kecamatan Gunug Talang Kabupaten Solok.Penelitian ini memakai metode penelitian yuridis empiris untuk melihat bagaimana mekanisme pendirian BUMnag di Nagari Cupak kecamatan Gunung Talang Kabupaten Solok. Berdasarkan hasil penelitian ini ditemukan Pertama, mekanisme pendirian Badan Usaha Milik Nagari (BUMNag) yang bernama Badan Usaha Milik Nagari Usali di Nagari Cupak Kecamatan Gunung Talang Kabupaten Solok dibentuk melalui musyawarah Nagari dengan dihadiri tokoh-tokoh masyarakat. BUMNag Usali Cupak telah berperan dalam pemberdayaan masyarakat dan peningkatan kualitas perokonomian di Nagari Cupak melalui unit usaha pertama Konveksi, keduA Agen BNI/PPOB BNI dan yang ketiga adalah Tabungan Bajapuik atau simpan pinjam. Kegiatan yang ini yang telah memberikan dampak terhadap peningkatan ekonomi masyarakat.

Kata kunci : Badan Usaha Milik Nagari; Pemberdayaan; Kesejahteraan Masyarakat
\end{abstract}




\title{
THE ROLE OF THE ESTABLISHMENT OF THE NAGARI OWNED ENTERPRISES BASED ON ACT NO. 6 OF 2014 CONCERNING VILLAGE IN THE ECONOMIC IMPROVEMENT EFFORTS IN NAGARI CUPAK SUB- DISTRICT OF GUNUNG TALANG DISTRICT, SOLOK.
}

\begin{abstract}
This study aims to describe and understand first, What is the mechanism of establishment Nagari-Owned Enterprises (BUMNag) in Nagari Cupak, Gunung Talang sub-district, Second Solok Regency, How is the role of Nagari-Owned Enterprises (BUMNag) in improving the welfare of the Nagari Cupak community Gunug Talang District Solok Regency. This study used juridical empirical research methods to see how the mechanism establishment BUMnag in Nagari Cupak, Gunung Talang sub-district, Solok Regency. Based on the results of this study, it can be concluded that the mechanism establishment Nagari-Owned Enterprises (BUMNag) named Nagari Usali-Owned Enterprises in Nagari Cupak, Gunung Talang District, Solok Regency was formed through the Nagari deliberations in the presence of community leaders. BUMNag Usali Cupak has played a role in community empowerment and economic quality improvement in Nagari Cupak through the convection business unit, BNI / PPOB BNI agents and Bajapuik Savings or savings and loans. This activity has had an impact on improving the community's economy.

Keywords: Nagari-Owned Enterprises; Empowerment; Community Welfare
\end{abstract}




\section{PENDAHULAN A. Latar Belakang}

Pemerintah memberikan kesempatan kepada daerah untuk menyelenggarakan otonomi daerah. berdasarkan Pasal 18 Undang- Undang Dasar Negara Republik Indonesia Tahun 1945 menyatakan bahwa pembagian Daerah Indonesia atas daerah besar dan kecil dengan bentuk dan susunan pemerintahannya yang ditetapkan oleh UndangUndang. ${ }^{1} \quad$ Penyelenggaraan perekonomian di Indonesia dilaksanakan dengan tujuan guna mencapai masyarakat yang adil dan makmur secara merata dengan berasaskan Pancasila dan berlandaskan amanat Pasal 33 UUD NRI 1945.

$$
\text { Kelahiran Undang- }
$$

Undang Nomor 6 Tahun 2014 tentang Desa selanjutnya disebut UU Desa, menempatkan Desa tidak sekedar sebagai objek pembangunan tetapi telah merubah cara pandang Desa sebagai pelaku atau subjek pembangunan dalam kerangka Negara Kesatuan Republik Indonesia. Desa merupakan sub sitem yang terkecil dan terendah dalam struktur pemerintahan negara yang terdekat dengan masyarakat dan secara riil langsung menyentuh kebutuhan masyarakat untuk disejahterakan. ${ }^{2} \quad$ Untuk mengurus kepentingan masyarakat desa setempat maka dibentuk suatu bentuk kelembagaan yang mana

${ }^{1}$ Undang-Undang Dasar Negara

Republik Indonesia Tahun 1945

2 Ni'matul Huda, Hukum Pemerintahan Desa, Malang, Setara Press, 2015, Hlm 36. bentuk kelembagaan ini berupa Badan Usaha Milik Desa (BUMDes).

Pengakuan akan otonomi desa juga ada dalam UU No.32 tahun 2004. Dalam UU itu dijelaskan tentang definisi desa, yakni suatu kesatuan masyarakat hukum yang mempunyai susunan asli berdasarkan hak asal usul yang bersifat istimewa, sebagaimana dimaksud dalam penjelasan pasal 18 Undang-Undang Dasar 1945. Basis pemikiran dalam pengaturan mengenai Pemerintahan Desa adalah keanekaragaman, partisipasi, otonomi asli, demokratisasi, dan pemberdayaan masyarakat. Sehingga dapat disimpulkan, baik UU No.32 tahun 2004 maupun PP No. 72 tahun 2005 itu memang mengamanatkan adanya desentralisasi kekuasaan bagi pemerintahan desa. $^{3}$

BUMDes lahir sebagai suatu pendekatan baru dalam usaha peningkatan ekonomi desa berdasarkan kebutuhan dan potensi desa. Pengelolaan BUMDes sepenuhnya dilaksanakan oleh masyarakat desa, yaitu dari desa, oleh desa dan untuk desa. Cara kerja BUMDes adalah dengan jalan menampung kegiatan-kegiatan ekonomi masyarakat dalam sebuah bentuk klembagaan atau badan usaha yang dikelola secara professional, namun tetap berstandar pada potensi asli desa. Hal ini dapat

\footnotetext{
${ }^{3}$ Coristya Berlian Ramadana Heru Wibawanro, Suwondo, Keberadaan Badan Usaha Milik Desa (BUMDES) Sebagai Penguatan Ekonomi Desa, Pengembangan Potens iEkonomi Desa Melalui Badan Usaha Milik Desa Pondok Salam Kabupaten Purwakarta, Jurnal Dharmakarya Vol 5 No 1, 2016, Bandung, Perpustakaan Universitas Padjajaran, hlm 1.
} 
menjadikan usaha masyarakat lebih produktif dan efektif. ${ }^{4}$

Keberadaan BUMDes ini diharapkan mampu mendorong kehidupan ekonomi di pedesaan. Adanya aturan ini membuat pemerintah untuk dapat memulai mendirikan Badan Usaha Milik Desa serta mulai menerapkannya pada desa-desa atau dengan nama lainnya yang setara desa. Undang-Undang tentang Desa ini diharapkan dapat mempercepat pembangunan di Desa atau sebutan dengan nama lain seperti Nagari di Sumatera Barat, segala potensi di daerah juga dapat lebih diberdayakan untuk kesejahteraan rakyat $^{5}$. Sebagai wakil negara, desa wajib melakukan pembangunan baik pembangunan fsik maupun pembanguan sumber daya manusia, sebagai upaya peningkatan kualitas hidup dan kehidupan untuk sebesarbesarnya kesejahteraan masyarakat desa. Sejak berlakunya Undang-Undang Nomor 23 Tahun $2014 \quad$ Tentang Pemerintahan Daerah, penerapan era desentralisasi pun menjadikan daerah-daerah memiliki otonomi yang seluasluasnya untuk mengatur urusan rumah tangganya sendiri sesuai dengan kebutuhan dan potensi daerah masing-masing. Lahirnya otonomi menjadikan daerah lebih leluasa mengatur urusan dalam bidang

4 Reza M Zulkarnaen,
Pengembangan Potensi Ekonomi Desa Melalui Badan Usaha Milik Desa Pondok Salam Kabupaten Purwakarta, Jurnal Adminitrasi Publik (JAP) Vol 1 No 6, 2017, Malang, Fakultas Ilmu Administrasi Universitas Brawijaya, hlm 1071.

5 Budiman Sudjatmiko dan Yando Zakaria, Desa Kuat, Indonesia Hebat. Pustaka Yustisia, Yogyakarta, 2015 hal 15. pemerintahan, pembangunan dan juga ekonomi selagi tidak bertentangan dengan peraturan perundang-undangan.

Termasuk di dalamnya adalah Pemerintahan Desa atau Nagari untuk sebutan di Sumatera Barat. Dalam Pasal 1 angka 4 Peraturan Daerah Kabupaten Solok Nomor 2 Tahun 2015 dijelaskan bahwa: "Nagari adalah kesatuan masyarakat hukum yang memiliki batas wilayah yang berwenang untuk mengatur urusan pemerintahan, kepentingan masyarakat setempat berdasarkan prakarsa msyarakat, hak asal usul, dan/atau hak tradisional yang diakui dan dihormati dalam sistem pemerintahan Negara Kesatuan Republik Indonesia”.

Badan Usaha Milik Desa adalah badan usaha yang seluruh atau sebagian besar modalnya dimiliki oleh Desa melalui penyertaan secara langsung yang berasal dari kekayaan Desa yang dipisahkan guna mengelola aset, jasa pelayanan, dan usaha lainnya untuk sebesar-besarnya kesejahteraan masyarakat Desa. ${ }^{6}$ BUM Des diatur lebih lanjut dalam Peraturan Pemerintah Nomor 43 Tahun 2014 Tentang Peraturan Pelaksanaan Undang-Undang Nomor 6 Tahun 2014 Tentang Desa yaitu dalam BAB VIII Pasal 132 ayat (1) bahwa desa dapat mendirikan BUM Desa, pasal 137 ayat (1) huruf $b$ untuk mengembangkan kegaiatan usahanya, BUM Desa dapat mendirikan unit usaha BUM Desa, ayat (3) pendirian, pengurusan dan pengelolaan unit usaha BUM Desa sebagaimana dimaksud

${ }^{6}$ Pasal 6 Undang-Undang Nomor 6 Tahun 2014 Tentang Desa. 
pada ayat (1) dilaksanakan sesuai dengan ketentuan peraturan perundangundangan.

Badan Usaha Milik Nagari (BUMNag) lahir sebagai suatu pendekatan baru dalam usaha peningkatan ekonomi desa berdasarkan kebutuhan dan potensi desa. Dalam Pengolahan BUMNag sepenuhnya dilaksanakan oleh masyarakat desa, yaitu dari desa, oleh desa, dan untuk desa. Pembentukan BUMNag ini sangat penting dan bermanfaat sekali bagi masyarakat untuk meningkatkan taraf perekonomian mereka. BUMDes/BUMNag ini merupakan jawaban dari Pasal 33 UUD 1945. BUMNag diharapkan dapat menjadi pilar kesejahteraan bangsa, karena BUMDes/BUMNag tidak lain merupakan usaha didirikan atas dasar komitmen bersama masyarakat bawah, masyarakat akar rumput, yaitu masyarakat desa/nagari, untuk saling bekerja sama, bergotong royong, dan menggalang kekuatan ekonomi rakyat. $^{7}$ Menurut data Simulasi Dana Alokasi Desa pada buku Budiman Sudjatmiko, Kabupaten Solok memiliki 15 Kecamatan dengan total keseluruhan 76 Nagari. Salah satu dari kecamatan di Kabupaten Solok yaitu Kecamatan Gunung Talang Kabupaten Solok, Di Kecamatan ini terdapat 9 Nagari, diantaranya ada Nagari Cupak, Nagari yang sangat indah dan asri di kaki Gunung Talang Nagari Cupak berada di kaki Gunung Talang, sekitar 40 $\mathrm{Km}$ arah Timur Kota Padang menuju Kota Solok. tepatnya di perlintasan jalur Lintas Sumatra antara Kota SolokPadang yang di apit oleh beberapa Nagari diantaranya Nagari Talang, Nagari JawiJawi, Nagari Gantung Ciri, Nagari Koto Anau, Koto Baru dan Muaro Paneh. Nagari Cupak merupakan salah satu penghasil utama beras Solok dengan kualitas terbaik, penulis memilih penelitian di Nagari Cupak dikarenakan telah dimulai pendirian Badan Usaha Milik Nagari. Pemerintah daerah membiayai setiap nagari di wilayah Sumatera Barat dalam hal urusan Pemerintah Daerah yang diselenggarakan oleh Nagari berasal dari dana Anggaran Pendapatan dan Belanja Daerah (APBD) serta dalam hal urusan Pemerintah yang diselenggarakan oleh nagari berasal dari dana Anggaran Pendapatan dan Belanja Negara (APBN). ${ }^{8}$

Di Provinsi Sumatera Barat hanya ada 14 kabupaten dan kota yang sudah mendirikan BUMNag pada tahun 2016 padahal di Sumatera Barat jumlah kabupaten dan kota ada 19. Tidak semua nagari yang ada di kabupaten/kota mampu mendirikan BUMNag, hal ini banyak faktor yang mempengaruhinya, seperti sumber daya manusia untuk menjadi pengurus masih rendah, pembinaan dari provinsi dan kabupaten yang masih lemah, pemahaman pemerintah nagari dan

${ }^{7}$ Hendri Andi Mesta, Yolandafitri Zulvia, Jurnal Sembada 2018, Penerbit PKN STAN Politeknik Keuangan Negara, Jakarta..

${ }^{8}$ Profil Nagari Cupak, Kecamatan Gunung Talang Kabupaten Solok. 
masyarakat akan pentingnya BUMNag yang masih rendah. ${ }^{9}$

Berdasarkan hal ini, maka penulis tertarik untuk meneliti pelaksanaan dari BUMNag dengan judul PERANAN PENDIRIAN BADAN USAHA MILIK NAGARI BERDASARKAN UNDANG-UNDANG

NOMOR 6 TAHUN 2014

TENTANG DESA DALAM

UPAYA PENINGKATAN

EKONOMI MASYARAKAT

DI NAGARI CUPAK KECAMATAN GUNUNG

TALANG KABUPATEN SOLOK.

B. Perumusan Masalah

Perumusan maslah dalam penelitian ini adalah :

1. Bagaimanakah mekanisme Badan Usaha Milik Nagari dalam upaya peningkatan Ekonomi masyarakat di Nagari Cupak Kecamatan Gunung Talang Kabupaten Solok?

2. Bagaimanakan peranan Badan Usaha Milik Nagari di Nagari Cupak Kecamatan Gunung Talang Kabuaten Solok?

\section{Metode Penelitian}

Untuk menjawab permasalahan yang telah dirumuskan dalam penelitian ini, digunakan metode pendekatan yuridis sosiologis (empiris) yaitu penelitian yang berlandaskan pada kaidahkaidah hukum yang dilihat dari segi penerapannya.

9 RINDA - 2018

scholar.unand.ac.idhttp://scholar.u nand.ac.id/40328/2/BAB\%20I.pdf
Sedangkan sifat Penelitian yang dilakukan dalam penelitian ini adalah deskriptif analitis yaitu penelitian ini diharapkan dapat diperoleh gambaran yang menyeluruh dan lengkap mengenai proses pembentukan Badan Usaha Milik Nagari Cupak Kecamatan Gunug Talang Kabupaten Solok dan peranannya terhadap kesejahteraan ekonomi masyarakat setempat. Jenis data yang digunakan dalam penelitian ini meliputi data primer, data sekunder dan data tersier. Data primer merupakan semua data yang diperoleh dari sumber primer yakni sebagai data utama berupa informasi yang diperoleh langsung melalui penelitian lapangan (field research) yang berkaitan dengan proses pembentukan Badan Usaha Milik Nagari Cupak Kecamatan Gunung Talang Kabupaten Solok. Disamping itu, juga menggunakan data sekunder sebagai data yang diperoleh dari penelusuran kepustakaan yang bersumber pada ketentuan peraturan perundang-undangan,

Risalah dan berbagai peraturan lainnya. Sedangkan data tersier yaitu berupa data pelengkap yang mendukung data primer dan data sekunder.

\section{PEMBAHASAN}

\section{A. Peranan Badan Usaha Milik Nagari (BUMNag) Dalam Peningkatan Kesejahteran}




\section{Masyarakat Nagari Cupak Kecamatan Gunung Talang Kabupaten Solok. \\ Lahirnya \\ Undang-}

Undang Nomor 6 Tahun 2014 tentang Desa membuat kebijakan tentang desa dalam memberi pelayanan, peningkatan peran serta dan pemberdayaan masyarakat desa yang ditujukan bagi kesejahteraan masyarakat. Lahirnya otonomi daerah serta dalam era globalisasi, maka pemerintah daerah dituntut memberikan pelayanan yang lebih prima serta memberdayakan masyarakat sehingga masyarakat ikut terlibat dalam pembangunan untuk kemajuan daerahnya, karena masyarakatlah yang lebih tahu apa yang mereka butuhkan serta pembangunan yang dilakukan akan lebih efektif dan efisien, dan dengan sendirinya masyarakat akan mempunyai rasa memiliki dan tanggung jawab. ${ }^{10}$

Besarnya kewenangan Pemerintahan Desa dalam hal luas dan isi disatu pihak memberi peluang bagi upaya mendorong tumbuh dan berkembangnya otonomi desa, namun disisi lain bukan mustahil menjadi ancaman bagi perkembangan desa dimasa akan datang. Kewenangan desa yang luas ditunjang oleh sumber keuangan yang menjanjikan tampak seperti "pisau belati bermata dua". Dalam konteks

\footnotetext{
P.L. Rika Fatimah, Mengembangkan Kualitas Usaha Milik Desa (Q-BUMDES) Untuk Melestarikan Ketahanan EkonomiMasyarakat dan Kesejahteraan Adaptif Perancangan Sistem Kewirausahaan Desa dengan Menggunakan Model Tetrapreneur, Jurnal Studi Pemuda Vol 7 No 2, 2018, Jogjakarta, Fakultas Ekonomi Dan Bisnis Universitas Gadjah Mada, hlm 122.
}

Badan Permusyawarahan Desa (BPD) misalnya, sekalipun dinyatakan dalam Undangundang Badan Permusyawarahan Desa berada diluar batasan pengertian Pemerintahan Desa, namun praktis Badan Permusyawarahan Desa (BPD) tak memiliki fungsi pengawasan terhadap akuntabilitas kepala desa. ${ }^{11}$

Salah satu program yang diluncurkan pemerintah untuk peningkatan kesejahteraan masyarakat adalah dengan membentuk Dana Desa. Dana Desa yang sudah dimulai semenjak tahun 2014 lalu mulaiterealisasi di ribuan desa yang tersebar di 33 provinsi. Tujuan utama diluncurkannya adalah untuk mewujudkan desa yang sejahtera dan makmur di Indonesia. Jumlah Dana Desa yang diberikan pemerintah sebesar Rp 1 Miliar yang mulai direalisasikan tahun 2016, memiliki potensi besar. Tanah Datar adalah salah satu Kabupaten yang berada di Provinsi Sumatera Barat, Indonesia, dengan ibu kota Batusangkar dengan jumlah Nagari 75 Kenagarian. Berdasarkan Rincian Dana Desa Tahun Anggaran 2017 menurut Kabupaten dan Kota, alokasi Dasar Dana Desa untuk Provinsi Sumatera Barat adalah sebesar Rp 668.570.176.000. dan dana inilah yang di jadikan sebagai Modal dalam pendirian BUMNag. ${ }^{12}$ 
Dengan didirikannya BUMNag Usali nagari cupak maka ada beberapa Jenis Usaha yang dapat dikelola oleh suatu Nagari berdasarkan Pasal 22 angka (2) Peraturan Daerah Kabupaten Solok Nomor 2 Tahun 2015 terdiri dari :
a. Jasa;
b. Penyaluran Sembako;
c. Perdagangan;
d. Pengolahan

Hasil

Pertanian; dan/ atau

e. Industri kecil Rumah Tangga

Tiap Nagari berhak untuk memilih dan menentukan jenis usaha yang ingin mereka kembangkan. Seperti Nagari Cupak, dalam Peraturan Nagari Cupak Nomor 6 Tahun 2018, Kenagarian Cupak menetapkan beberapa jenis usaha mereka. Hal ini berdasarkan Pasal 22 ayat (2) Peraturan Nagari Cupak Nomor 6 Tahun 2018 tentang Pembentukan Badan Usaha Milik Nagari yang berbunyi: (2) Unit Usaha dalam BUMNag meliputi:

a. Pengelolaan objek wisata (wisata air, out bond, wisata agro, pondok oleholeh dan kebun binatang);

b. Pengadaan sarana dan prasarana produksi pertanian;

c. Pemasaran produk pertanian, perkebunan dan perikanan.

Melalui jenis usaha yang dikembangkan dalam BUMNag, yang saat ini sedang

USAHA MILIK NAGARI (BUMNag) BERBASIS SYARIAH DI NAGARI SUNGAYANG KABUPATEN TANAH DATAR diakses melalui http://ecampus.iainbatusangkar.ac.id/ojs/ind ex.php/proceedings/article/view/1536/1252 berjalan ada tiga, pertama Usaha Konveksi, kedua Usaha Agen BNI 46 dan yang ketiga adalah Usaha Tabungan Bajapuik dan simpan pinjam. Usaha-usaha ini tentunya dapat memperoleh keuntungan finansial dan dapat meningkatkan perekonomian Nagari.

Keberadaan Badan Usaha Milik Desa menjadi salah satu pertimbangan untuk menyalurkan inisiatif masyarakat desa, mengembangkan potensi desa, dan adanya penyertaan modal dari pemerintah desa dalam bentuk pembiayaan dan kekayaan desa yang diserahkan untuk mengelola dana bergulir dan simpan pinjam. ${ }^{13}$

BUMNag sebagai lembaga sosial berpihak kepada kepentingan masyarakat nagari melalui konstribusinya dalam penyediaan peluangusaha dan fasilitas pemberdayaaan ekonomi masyarakat. Sedangkan sebagai lembaga komersial bertujuan mencari keuntungan melalui usaha tabungan bajapuik atau simpan pinjam. ${ }^{14}$

$\begin{array}{cc}\text { Pengurusan } & \text { BUMNag } \\ \text { terpisah dari } & \text { organisasi }\end{array}$ pemerintahan Nagari. Pengurus dan pengelolanya tidak menjabat di pemerintahan kenagarian. Peraturan mengenai diaturnya pengurus dan pengelolaan dari BUMNag ini didasarkan kepada Anggaran Dasar (AD) dan Anggaran Rumah Tangga

${ }^{13}$ Amelia Sri Kusuma Dewi," interpretasi Bentuk Badan Usaha Milik Desa Menurut undang-undang Nomor 6 Tahun 2014", Jurnal media Hukum.

${ }^{14}$ Wawancara dengan Direktur BUMNag Nagari Cupak, Bapak HOSRA Afrizoni, SE.MM Tanggal 4 Oktober 2019. 
(ART) yang telah disepakati secara bersama di Kenagarian Cupak. Hal ini dijelaskan pada Pasal 7 Peraturan Nagari Cupak Nomor 6 Tahun 2018 tentang Pembentukan Badan Usaha Milik Nagari.

BUMNag terdiri dari unit-unit usaha yang berbadan hukum yang mana unit usaha yang berbadan hukum dapat berupa perseroan terbatas yang merupakan persekutuan modal dibentuk dengan perjanjian untuk melakukan kegiatan usaha dengan modal yang sebgian besar dimiliki oleh BUMNag, dan lembaga bisnis dengan andil BUMNag sebesar 60 (enam puluh) persen yang kepemilikan sahamnya berasal dari BUMNag, masyarakat, dan pihak ketiga.

Berdasarkan Pasal 8

Peraturan Nagari Cupak Nomor 6 Tahun 2018 tentang Pembentukan Badan Usaha Milik Nagari, susunan kepengurusan organisasi pengelola BUMNag terdiri dari:
a. Penasehat
b. Pelaksana Operasional
c. Pengawas
Penasehat
dijabat
langsung oleh Wali Nagari. Wali Nagari akan selalu mengkoordinir, memberikan masukan, saran serta nasehat untuk pembangunan dan pengelolaan BUMNag di nagari. Kewajiban dari penasehat ini yaitu memberikan nasehat kepada pelaksana operasional memberikan saran dan pendapat mengenai masalah yang dihadapi, dan mengendalikan pelaksanaan kegiatan pengelolaan BUMNag. Berdasarkan pada Pasal 9 ayat (3), penasehat berwenang untuk:

a. Meminta penjelasan dari pelaksana operasional mengenai persoalan yang menyangkut pengelolaan usaha Nagari; dan

b. Melindungi usaha Nagari terhadap hal-hal yang dapat menurunkan kinerja BUMNag.

Pelaksana operasional diatur dalam Pasal 10 sampai Pasal 17 Peraturan Nagari Cupak Nomor 6 Tahun 2018 tentang Pembentukan BUMNag. Pelaksana operasional dipimpin oleh seorang direktur dan mempunyai tugas mengurus serta mengelola BUMNag sesuai dengan Anggaran Dasar dan Anggaran Rumah Tangga. Dalam melaksanakan kewajibannya, direktur dapat menunjuk sekretaris dan bendahara untuk mengurus pencatatan dan administrasi usaha dan fungsi operasional bidang usaha. Sekretaris dan Bendahara juga dapat dibantu oleh karyawan sesuai dengan kebutuhan yang harus sesuai dengan tugas, tannggungjawab, pembagian peran dan pembagian kerja lainnya.

Pengurusan pengelola BUMNag selanjutnya yaitu pengawas. Pengawas diatur dalam Pasal 18 Peraturan Nagari Cupak Nomor 6 Tahun 2018 tentang Pembentukan BUMNag. Pengawas terdiri dari ketua, wakil ketua merangkap anggota, sekretaris merangkap anggota, dan anggota. Pengawas berwenang untuk menyelenggarakan rapat untuk membahas kinerja BUMNag dan untuk menyelenggarakan Rapat Umum Pengawas.

$$
\text { Dalam menyikapi }
$$

keadaan nagari, nagari harus memiliki pemasukan untuk 


\begin{abstract}
dimasukkan ke dalam Pendapatan Asli Nagari, sehingga dapat membantu perekonomian masyarakat. Masyarakat nagari harus mempunyai sektor keuangan yang bagus sehingga terbentuk ekonomi yang kuat, hingga masyarakat yang membutuhkan dapat dibantu dengan segala bantuan yang ada. ${ }^{15}$
\end{abstract}

BUMNag Usali Cupak kedepan nya berpeluang dalam pengembangan yang lebih besar dan luas karena didukung dengan adanya partisipasi masyarakat. Partisipasi masyarakat memiliki point penting dengan adanya keberadaan BUMNag Artinya peran masyarakat berpengaruh pada keberhasilan organisasi BUMNag bila partisipasi masyarakat rendah tentu akan rendah pula kebersilan BUMNag Usali. Sejauh ini karena usia BUMNag nagari Cupak masih terlalu muda namun sudah dapat memberikan peningkatan pemberdayaan masyarakat karena jenis usaha yang di lakukan oleh BUMNag Usali Cupak banyak memberikan kemudahan dan penigkatan perekonomian terutama dalam usaha konveksi yang telah dapat menyerap lapangan pekerjaan bagi ibu- ibu rumah tangga yang tidak bekerja namun mempunyai keahlian di bidang menjahit. ${ }^{16}$

\section{Menurut Irwan}

Prayitno, BUMNag tidak menjadikan pengusaha Minang sebagai bawahan, akan tetapi

${ }^{15}$ Wawancara dengan Bapak Hosra Afizoni direktur BUMnag Nagari Cupak, Tanggal 2 Oktober 2019.

${ }^{16}$ Wawancara dengan sekretaris Bumnag Nagari Cupak Tanggal 29 September 2019. sebagai mitra. Dengan demikian, BUMNag ini secara administrasi tidak memiliki karyawan (bawahan), namun faktanya memiliki karyawan (para pemimpin), yaitu pengusaha Minang itu sendiri. Dengan demikian, BUM Nagari mengapresiasi pengusaha Minang sebagai pemimpin di tempat usahanya sendiri. Oleh karena itu pembentukan BUMNag yang bertujuan untuk Nagari juga berawal dari masyarakat nagari yang secara bersama-sama bekerja dan berusaha memajukan wilayah nagari tanpa ada karyawan (bawahan).

\section{PENUTUP}

Mekanisme Pendirian Badan Usaha Milik Nagari (BUMNag) Usali di Nagari Cupak Kecamatan Gunung Talang Kabupaten Solok dibentuk melalui musyawarah nagari dengan dihadiri tokohtokoh masyarakat hingga membentuk suatu kesepakatan untuk membangun BUMNag yang nantinya dapat meningkatkan perekonomian masyarakat. Setelah mencapai kesepakatan itu maka pemerintah membentuk Peraturan Nagari. Kehadiran BUMNag Sebagai upaya pemerintah dalam menanggulangi masalah perekonomian masyarakat dengan cara memobilisasi pengelolaan asset desa serta membantu dan mendukung usaha kecil masyarakat dalam memenuhi kebutuhan hidupnya. BUMNag Usali Nagari Cupak berperan dalam usaha pemberdayaan Masyarakat di nagari Cupak walaupun masih tergolong sangat muda dalam usianya namun kedepan nya 


\begin{abstract}
berpeluang dalam pengembangan yang lebih besar dan luas karena didukung dengan adanya partisipasi masyarakat. Jenis usaha yang di lakukan oleh BUMNag Usali Cupak banyak memberikan kemudahan dan penigkatan perekonomian terutama dalam usaha tabungan bajapuik dan konveksi yang telah dapat menyerap lapangan pekerjaan dan meningkatkan pemberdayaan masyarakat nagari Cupak. Berdasarkan hasil penelitian yang telah disimpulkan maka saran yang dapat disampaikan adalah BUMNag Usali Cupak sebuah badan usaha yang berbadan hukum supaya disertai dengan akta notaris serta akta pendirian Badan usaha sehingga dapat terdaftar di Kementerian Hukum dan HAM. Bagi masyarakat Nagari Cupak hendaknya ikut serta secara langsung dalam bersinergi dan mendukung usaha BUMNag Usali Nagari Cupak dalam hal pengelolaan dan penggunaan usaha agar mempercepat terwujudnya peningkatan perekonomian Msayarakat Cupak.
\end{abstract}

\section{DAFTAR PUSTAKA}

\section{Buku}

Raharjo, Handri. 2013. Hukum Perusahaan. Yogyakarta : Pustaka Yustisia.

Sudjatmiko, Budiman, dan Yando Zakaria. 2015.

Desa Kuat, Indonesia Hebat, Yogyakarta : Pustaka Yustisia
Sungguno, Bambang. 2003. Metode Penelitian Hukum. Jakarta : Radja Grafindo.

Sukanto, Soerjono. 2006. Pengantar Penelitian Hukum. Jakarta : UI-Pers.

\section{Peraturan Perundang-}

\section{Undangan}

Undang-Undang Nomor 6

Tahun 2014 tentang Desa

$\begin{array}{crr}\text { Peraturan Daerah } & \text { Kabupaten } \\ \text { Solok Nomor } & 2 & \text { Tahun } \\ 2015 & \text { tentang } & \text { Pedoman } \\ \text { Pembentukan } & \text { dan } \\ \text { Pengelolaan Badan Usaha } \\ \text { Milik Nagari } & \\ \text { Peraturan Nagari } & \text { Nomor } 6 \\ \text { Tahun 2018 } & \text { tentang } \\ \text { Pembentukan } & \text { Badan } \\ \text { Usaha Milik } & \text { Nagari } \\ \text { Cupak. } & \end{array}$

Jurnal.

Amelia Sri Kusuma Dewi," Interpretasi Bentuk Badan Usaha Milik Desa Menurut Undang-Undang Nomor 6 Tahun 2014", Jurnal Media Hukum.

Coristya Berlian Ramadana Heru Wibawanro, Suwondo, Keberadaan Badan Usaha Milik Desa (BUMDES) Sebagai Penguatan Ekonomi Desa, Pengembangan Potensi Ekonomi Desa Melalui Badan Usaha Milik Desa Pondok Salam Kabupaten Purwakarta, Jurnal Dharmakarya Vol 5 No 1, 2016, Bandung, Perpustakaan Universitas Padjajaran, hlm 1.

Hendri Andi Mesta, Yolandafitri Zulvia, Jurnal Sembada 2018, Penerbit PKN STAN, Jakarta, Politeknik Keuangan Negara.

Martinus Aditya Pardiyanto, Konflik SosialDan 
Ekonomi Sebagai Dampak

Undang-Undang Nomor 6

Tahun 2014 Tentang Desa, Jurnal Ius Constituendum

Vol 2 No 2, 2017,

Semarang, Program Pasca

Sarjana Universitas

Semarang.

P.L. Rika Fatimah,

Mengembangkan Kualitas

Usaha Milik Desa (Q-

BUMDES) Untuk

Melestarikan Ketahanan

EkonomiMasyarakat dan

Kesejahteraan Adaptif

Perancangan Sistem

Kewirausahaan Desa

dengan Menggunakan

Model Tetrapreneur,

Jurnal Studi Pemuda Vol 7

No 2, 2018, Jogjakarta,

Fakultas Ekonomi Dan

Bisnis Universitas Gadjah

Mada

Reza M Zulkarnaen,

Pengembangan Potensi

Ekonomi Desa Melalui

Badan Usaha Milik Desa

Pondok Salam Kabupaten

Purwakarta, Jurnal

Adminitrasi Publik (JAP)

Vol 1 No 6, 2017, Malang,

Fakultas Ilmu

Administrasi Universitas

Brawijaya.

\section{Internet}

Agung Septian Wijarnako, Peran Badan Usaha Milik Desa Dalam Pemberdayaaan Masyarakat, diakses dari http://eprints.upnjatim.ac.i d/4487/1/file1

HI Rinda - 2018

scholar.unand.ac.id

diakses 3 Oktober 2019

Elfina Yenti Nita Fitria Diatul

Fajri Rencana Strategis

Badan Usaha Milik Nagari

(Bumnag) Berbasis

Syariah di Nagari

Sungayang Kabupaten
Tanah Datar diakses melalui

http://ecampus.iainbatusan gkar.ac.id/ojs/index.php/pr oceedings/article/view/153 $\underline{6 / 1252}$ 